\title{
Natural infection by Trypanosoma cruzi in triatomines and seropositivity for Chagas disease of dogs in rural areas of Rio Grande do Norte, Brazil
}

\author{
Yannara Barbosa Nogueira Freitas ${ }^{[1]}$, Celeste da Silva Freitas de Souza ${ }^{[2]}$, \\ Jamille Maia e Magalhães ${ }^{[1]}$, Maressa Laíse Reginaldo de Sousa[1], \\ Luiz Ney d'Escoffier ${ }^{[2]}$, Tânia Zaverucha do Valle ${ }^{[2]}$, Teresa Cristina Monte Gonçalves ${ }^{[3]}$, \\ Hélcio Reinaldo Gil-Santana ${ }^{[4]}$, Thais Aaparecida Kazimoto[1] \\ and Sthenia Santos Albano Amora ${ }^{[1]}$
}

\begin{abstract}
[1]. Centro de Ciências Agrárias, Universidade Federal Rural do Semi-Árido, Mossoró, RN, Brasil.
[2]. Laboratório de Imunomodulação e Protozoologia, Instituto Oswaldo Cruz, Fundação Oswaldo Cruz, Rio de Janeiro, RJ, Brasil. [3]. Laboratório Interdisciplinar de Vigilância Entomológica em Diptera e Hemiptera, Fundação Oswaldo Cruz, Rio de Janeiro, RJ, Brasil.
\end{abstract}

[4]. Laboratório de Diptera, Fundação Oswaldo Cruz, Rio de Janeiro, RJ, Brasil.

\begin{abstract}
Introduction: Chagas disease is caused by the protozoa Trypanosoma cruzi. Its main reservoir is the domestic dog, especially in rural areas with favorable characteristics for vector establishment and proliferation. The aims of this study were to collect data, survey and map the fauna, and identify $T$. cruzi infection in triatomines, as well as to assess the presence of anti-T. cruzi antibodies in dogs in rural areas of the municipality of Mossoró, Brazil. Methods: An active entomologic research was conducted to identify adult specimens through an external morphology dichotomous key. The analysis of natural infection by T. cruzi in the insects was performed by isolation in culture and polymerase chain reaction. The antibody testing for T. cruzi in dogs was performed by enzyme-linked immunosorbent assay and indirect immunofluorescence assay. Results: A total of 68 triatomines were captured, predominantly the Triatoma brasiliensis brasiliensis (Neiva 1911) species. The vector mapping displayed areas with greater risk for parasite transmission. Of the examined triatomines (51 specimens), $41.2 \%$ (21/51) were positive on polymerase chain reaction, and all were negative on culture. In the serum testing, $11 \%(25 / 218)$ of dogs were seropositive, but no association was found between the serologic results and the presence and infection by $T$. cruzi in triatomines. Conclusions: This study demonstrated the movement of T. cruzi in the studied area, by the presence of vectors and naturally infected domestic reservoirs. The mapping of the studied rural area demonstrates the risk of disease transmission.
\end{abstract}

Keywords: Chagas disease. Vector. Domestic reservoir. Diagnosis. Zoonosis.

\section{INTRODUCTION}

Chagas disease (CD) is an anthropozoonosis caused by the protozoan Trypanosoma cruzi and is typically transmitted by triatomines, vectors of the Triatominae family (Hemiptera: Reduviidae), known as kissing bugs ${ }^{1-3}$.

In Brazil, the triatomine species responsible for CD transmission show wide spatial distribution and invasive potential, by adapting to homes and surrounding areas ${ }^{4}$. Vector presence can also be facilitated by constant alterations to the natural environment, caused by anthropic activities, leading to imbalances in ecosystems and modification of the behavior

Corresponding author: Dra. Sthenia Santos Albano Amora.

e-mail: sthenia@ufersa.edu.br

Received 20 July 2017

Accepted 18 April 2018 of insect vectors and wild animals that then enter homes for shelter and food ${ }^{5,6}$.

Domestic animals, especially dogs, have an important epidemiological role, because they serve as a link between domestic and wild cycles of $T$. cruzi ${ }^{7,8}$. Furthermore, they are an important disease sentinel, as their infection rates may reveal the potential of disease transmission to humans ${ }^{9-12}$.

However, for a better comprehension of the epidemiology of $\mathrm{CD}$, the whole cycle, including vectors, must be assessed. Therefore, identifying the vector species and infection type is crucial to understanding the biology and behavior and to evaluating the risk of disease transmission to humans and domestic animals ${ }^{4,13}$. An important tool used in epidemiological studies of vector-borne diseases is the mapping of the vector's spatial distribution, allowing for the prediction of T. cruzi transmissibility between triatomine species from spatial data ${ }^{14}$. 
Thus, this study aimed to gather data on animals in a rural area of Northeastern Brazil, as well as to map and investigate natural infection by $T$. cruzi in triatomines. The study also aimed to detect the presence of anti-T. cruzi antibodies in dogs in order to evaluate a possible association between infected dogs and the presence of triatomines infected by $T$. cruzi. and to determine environment-related factors.

\section{METHODS}

\section{Study area and sample definition}

The research was conducted in the rural area of Mossoró, located in the countryside of Rio Grande do Norte, Northeast region of Brazil. According to the State Department of Public Health, this area is considered endemic, because it presents a favorable environment for the vector's survival, due to the proximity of forests and a city dump, as well as an accumulation of debris and organic matter from animal husbandry. A total of 11 rural areas with environmental indicators for the occurrence of triatomines and a history of vector capture between 2008 and 2012, according to the Municipal Health Surveillance Department, were used in this study.

\section{Ethical considerations}

All of the 392 residences in these areas were visited between March and July 2014, and informed consent forms were obtained from residents that agreed to participate.

The project was approved by the Ethics Committee on Animal Use of the Federal Rural University of the Semi-Arid (Universidade Federal Rural do Semi-Arrido) (Ruling 62/2012 - Process 23091.002190/2012-75).

\section{Active entomologic collection}

The entomological collection consisted of a system of notification and collection by the residents of triatomines in their homes. Therefore, this method allowed for the monitoring of infestations by the local community.

Samples of different species of triatomines were presented to the residents to facilitate the recognition and capture of the insects, and they were given a polyethylene bottle containing holes in the lid to store the insects. After capture, the insects were sent to the Oswaldo Cruz Foundation Institute in Rio de Janeiro (FIOCRUZ-RJ), in a specific shipment for biological samples with a deadline of 24 hours, paid for by the institute. Upon receipt, the samples were immediately processed.

\section{Vector identification}

Properly packed triatomines were sent to the Laboratory of Leishmaniosis Transmitters of the Forensic Entomology Sector of the FIOCRUZ/RJ and identified by observing their external morphological characters, using the dichotomous key according to Lent \& Wygodzinsky ${ }^{15}$.

\section{Detection of natural infection by $T$. cruzi}

In order to detect $T$. cruzi infection, the intestinal contents of the insects were obtained by abdominal compression and processed for parasite isolation culture and polymerase chain reaction (PCR) techniques in the Laboratory of Immunomodulation and Protozoology of FIOCRUZ/RJ.

For the isolation, the obtained contents were seeded in tubes containing biphasic Novy-MacNeal-Nicolle + Liver Infusion Tryptose culture medium, supplemented with $10 \%$ fetal bovine serum and penicillin $(10,000 \mathrm{U} / \mathrm{mL})$. The tubes were kept in an incubator (FANEM, model 347 ) at $27^{\circ} \mathrm{C}$, and the cultures were examined weekly for four months by light microscopy using an Axioplan 2 (Zeiss $\left.{ }^{\circledR}\right)$ light microscope to verify positivity.

To detect $T$. cruzi deoxyribonucleic acid (DNA), phenolchloroform extraction was used to obtain DNA ${ }^{16}$, which was then subjected to a PCR with specific primers for T. cruzi (5' ASTCGGCTGATCGTTTTCGA 3' and 5' AATTCCTCCAAGCAGCGGATA $\left.3^{\prime}\right)^{17}$. The reaction was performed in a Step One Plus ${ }^{\text {TM }}$ Real-Time PCR System, using a rapid protocol of 20 seconds at $95^{\circ} \mathrm{C}$ followed by 40 cycles of 3 seconds at $95^{\circ} \mathrm{C}$ and 30 seconds at $60^{\circ} \mathrm{C}$. Ultrapure water was used as the negative control, and DNA obtained from axenic culture of the T. cruzi strain Y was used as the positive control. The amplified products were subjected to agarose gel electrophoresis at 1.5\% and stained with GelRed ${ }^{\mathrm{TM}}$ (Biotium), using TBE $1 \mathrm{x}$ buffer as an electric conductor.

\section{Anti-T. cruzi antibody evaluation in domestic dogs}

Blood samples from 218 domestic dogs were collected and, after centrifugation, the serum samples were stored in tubes and packed at $-20^{\circ} \mathrm{C}$ until the performance of the enzyme-linked immunosorbent assays (ELISA) and indirect immunofluorescence assays (IIF) at the Laboratory of Immunomodulation and Protozoology of FIOCRUZ/RJ.

For the anti-T. cruzi immunoglobulin $\mathrm{G}(\mathrm{IgG})$ antibody assay by IIF, immunofluorescent microscope slides with total T. cruzi antigen were produced in the Laboratory of Trypanosomatid Biology of FIOCRUZ/RJ. Previously tested positive canine serum and serum of dogs from non-endemic areas were used as positive and negative controls, respectively ${ }^{18}$. An anti-dog $\operatorname{IgG}\left(\right.$ FITC, Sigma ${ }^{\mathrm{TM}}$ ) was used as the conjugate. Serums with titration $\leq 1: 20$ were considered positive ${ }^{19}$.

A commercial kit produced by Bio-Manguinhos/FIOCRUZ and the anti-dog IgG conjugate (Peroxidase, Sigma ${ }^{\mathrm{TM}}$ ) were used for the ELISA. Samples were considered seropositive when they showed an optical density (OD) greater than the cut line (cut-off) obtained in each reaction.

As recommended by the World Health Organization for the diagnosis of human $\mathrm{CD}$, samples were only considered positive when they reacted in both serological tests.

\section{Data analysis}

The data for the statistical analysis were obtained from the identification form of the dogs, the serology results of the dogs' blood samples, and the presence of natural infection by T. cruzi in triatomine vectors.

To validate the serological tests, IIF test results were compared with those of a standard test. The analysis of agreement data was based on the sensitivity and specificity, using the statistical program GraphPad Prism version 6.01. The ELISA technique was used as the gold standard ${ }^{20,21}$. 
Data were entered into an electronic spreadsheet and transferred to the statistical programs SPSS 21.0 (Statistical Package for the Social Sciences) and STATA (Stata Corp., College Station, Estados Unidos) version 13.0, expressed in simple frequency and percentage, as well as prevalence ratio (PR) and confidence interval of 95\%, obtained by Poisson regression. A significance level of 5\% was considered.

\section{Mapping of triatomine capture areas}

The spatial distribution of the triatomines was established from geographic coordinates (latitude and longitude) of the capture sites, using a Global Positioning System (GPS) - Garmin e Trex ${ }^{\circledR}$ in the Universal Transverse Mercator (UTM) coordinate system, using the WGS-84 (or SIRGAS 2000). The free software Quantum GIS 2.8.3 was used to prepare a thematic map of the study area.

\section{RESULTS}

The study involved 279 residences, as described in Table 1, and insects were captured in 23 of them. A total of 68 triatomines were acquired, involving 54 from inside the residences and 14 from the peridomiciliary areas. In the residences in the study, 135 of them had one or more dogs, and blood samples were obtained from all 218 dogs present.

The captured triatomines corresponded to 25 nymphs of undetermined stage, and 43 adults, identified as $69.7 \%$ (30/43) Triatoma brasiliensis brasiliensis (Neiva 1911), 23.2\% (10/43) Triatoma pseudomaculata (Corrêa and Espínola 1964), 4.6\% (2/43) Rhodnius nasutus (Stal 1895), and 2.3\% (1/43) Panstrongylus lutzi (Neiva and Pinto 1923). The distribution of these species in the 11 rural localities is shown in Table 1. Of the 68 captured specimens, 51 (75\%) were under suitable conditions to obtain intestinal contents for $T$. cruzi analysis by isolation culture and PCR, including 24 adult specimens of T. b. brasilensis, one of T. pseudomaculata, one of R. nasutus, and 25 nymphs. Attempts to isolate T. cruzi by culture were negative in all triatomines, but $41.1 \%$ (21/51) of the samples were positive on PCR.

The results of the serological testing for T. cruzi showed that $11 \%(25 / 218)$ of the dogs tested were seropositive for both tests (ELISA and IIF). The sensitivity of the test was $53.2 \%$, and the specificity was $99.4 \%$, with confidence intervals of $38.1-67.9$ and $96.8-99.0$, respectively.

There was no association between the serologic results of the dogs and the presence and infection by T. cruzi in triatomines. The same was observed for dog-related factors, such as gender, role, and the presence of shelter or other animals (Table 2).

Triatomines were present in eight of the eleven rural localities included in this study, as shown in Figure 1.

\section{DISCUSSION}

The transmission of $\mathrm{CD}$ is undoubtedly influenced by sociocultural, political, economic, environmental, and historical factors $^{22}$, because the occurrence of this disease reflects how the population occupies and explores the environment in which it lives $^{23}$. Studies have shown that information about the vectors of $\mathrm{CD}$ in endemic areas is lacking, leading to the inefficiency of intervention programs ${ }^{24}$. Control programs of these areas should focus on educational measures adapted to the local context, elucidating the importance of the capture of the vectors and notification of the authorities to control the disease ${ }^{25}$.

The species found in this study are also distributed in other states of Brazil ${ }^{4,26}$; however, the Northeast Region of Brazil is considered the epicenter of dispersion of $T$. brasiliensis and $T$. pseudomaculata ${ }^{27}$. Geographical distribution of $R$. nasutus and $P$. lutz is restricted to certain regions of the Northeast region ${ }^{28}$, and both species are considered secondary vectors for T. cruzi transmission. However, research in Colombia has shown the relevance of these species, demonstrating that $59.4 \%$ of the secondary vectors had humans as the main food source ${ }^{29}$.

Studies have demonstrated that $T$. brasiliensis is the most important T. cruzi vector in Northeastern Brazil, with a high rate of infection ${ }^{30,31}$. This fact is attributed to the adaptability of this species to the hot and dry climate conditions of the Northeast region, where it only rains a few months out of the year ${ }^{32}$. This species of triatomine has high adaptability to a human habitat, corroborating the present study, which noted household and peridomiciliary presence of the same species. $T$. brasiliensis is classified as a domestic species due to the household presence of adults, nymphs, eggs, and molt ${ }^{32}$. This adaptability to the home area can also restrict its access to domestic and synanthropic animals as a food source ${ }^{33}$. Therefore, T. cruzi infection in these vectors may be crucial for the establishment of infection in humans and domestic animals.

Triatoma pseudomaculata is also important for the epidemiological surveillance of $\mathrm{CD}$, since it's the most frequent species after $T$. brasiliensis ${ }^{27,34}$. This species often shelters itself in locations of the residence that receive more sunlight, such as the rooftop ${ }^{30}$, and is well suited to the high temperatures observed in the study area ${ }^{35}$.

Regarding the testing for the presence of $T$. cruzi in triatomines, the negative results in the culture isolation may be associated with absence of viable parasites in inoculated samples, which is linked to the handling difficulty and death of the insects ${ }^{36}$, the contamination of the culture medium inhibiting the growth of the parasite, and the possibility that some strains of T. cruzi have a poor growth in culture ${ }^{37}$. However, infection of triatomines was confirmed by the detection of T. cruzi DNA by PCR in $41.17 \%$ of the samples. Therefore, we do not recommend the use of the isolation technique in culture to investigate the presence of $T$. cruzi in samples from the intestinal tract of insects.

The variation in the rate of infection by $T$. cruzi in this study may be associated with the dominant vector in each region, since each triatomine genera has a preference to certain natural or artificial ecotypes ${ }^{30,38}$, which may make them more susceptible to infection. For example, Coutinho et al..$^{30}$ observed that there is greater natural infection by $T$. cruzi in triatomines housed in wood piles, because these sites function as burrows of small animals, such as rodents and marsupials, that are wild reservoirs of $T$. cruzi. These animals then have a high capacity to infect the vectors ${ }^{38}$, while dogs, cats, and humans show much less infectivity to triatomines ${ }^{39}$. 
TABLE 1: Trypanosoma cruzi evaluation, identification of triatomines, and anti-T. cruzi antibody results in dogs from rural localities in the City of Mossoró, Rio Grande do Norte.

\begin{tabular}{|c|c|c|c|}
\hline $\begin{array}{l}\text { Rural locality/ } \\
\text { Geographic coordinates }\end{array}$ & $\begin{array}{l}\text { Total number of residences/ } \\
\text { Number of infected residences/ } \\
\text { Residences with infected triatomines }\end{array}$ & Triatomine species identified & $\begin{array}{l}\text { Total number of dogs/ } \\
\text { Number of residences with dogs/ } \\
\text { Residences with seropositive dogs }\end{array}$ \\
\hline $\begin{array}{l}\text { Sítio Umari } \\
5^{\circ} 07^{\prime} 52.8^{\prime \prime} \mathrm{S} \\
37^{\circ} 15^{\prime} 43.8^{\prime \prime} \mathrm{W}\end{array}$ & $2 / 2 / 1$ & $\begin{array}{c}\text { Nymph } \\
T \text { brasiliensis }\end{array}$ & $7 / 2 / 0$ \\
\hline $\begin{array}{l}\text { Sítio Sombra Grande } \\
5^{\circ} 06^{\prime} 17.5^{\prime \prime} \mathrm{S} \\
37^{\circ} 10^{\prime} 02.1^{\prime \prime} \mathrm{W}\end{array}$ & $4 / 0 / 0$ & - & $6 / 3 / 0$ \\
\hline $\begin{array}{l}\text { Settlement Melancias } \\
5^{\circ} 11^{\prime} 52.6^{\prime \prime} \mathrm{S} \\
37^{\circ} 14^{\prime} 09.7^{\prime \prime} \mathrm{W}\end{array}$ & $6 / 4 / 1$ & $\begin{array}{c}\text { Nymph } \\
\text { T. brasiliensis } \\
\text { T. pseudomaculata } \\
\text { Rhodnius nasutus }\end{array}$ & $6 / 4 / 0$ \\
\hline $\begin{array}{l}\text { Passagem de Oiticica } \\
5^{\circ} 14^{\prime} 48.5^{\prime \prime} \mathrm{S} \\
37^{\circ} 21^{\prime} 25.7^{\prime \prime} \mathrm{W}\end{array}$ & $1 / 0 / 0$ & - & 0 \\
\hline $\begin{array}{l}\text { Settlement Laginha } \\
5^{\circ} 15^{\prime} 14.2^{\prime \prime} \mathrm{S} \\
37^{\circ} 21^{\prime} 33.7^{\prime \prime} \mathrm{W}\end{array}$ & $1 / 0 / 0$ & - & $3 / 1 / 0$ \\
\hline $\begin{array}{l}\text { Sítio Canto da Farinha } \\
5^{\circ} 22^{\prime} 16.1^{\prime \prime} \mathrm{S} \\
37^{\circ} 18^{\prime} 39.6^{\prime \prime} \mathrm{W}\end{array}$ & $1 / 1 / 1$ & Nymph & $2 / 1 / 0$ \\
\hline $\begin{array}{l}\text { Settlement Lorena } \\
5^{\circ} 17^{\prime} 17.2^{\prime \prime} \mathrm{S} \\
37^{\circ} 20^{\prime} 03.2^{\prime \prime} \mathrm{W}\end{array}$ & $28 / 3 / 1$ & T. brasiliensis & $27 / 17 / 1$ \\
\hline $\begin{array}{l}\text { Settlement Passagem de Pedra } \\
5^{\circ} 09^{\prime} 23.9^{\prime \prime} \mathrm{S} \\
37^{\circ} 17^{\prime} 01.1^{\prime \prime} \mathrm{W}\end{array}$ & $106 / 3 / 0$ & T. brasiliensis & $67 / 44 / 12$ \\
\hline Total & $279 / 23 / 6$ & & $118 / 135 / 25$ \\
\hline
\end{tabular}

T.: Triatoma.

The present study utilized serologic tests for canine CD diagnosis because, although the primary infection with $T$. cruzi includes an initial phase with high parasitemia, this phase lasts a short time ${ }^{21,40}$, whereas T. cruzi antibodies persist at detectable levels for a long time ${ }^{39,41}$. Nevertheless, no serologic test is currently considered the gold standard for $\mathrm{CD}$, so the use of both ELISA and IIF for the diagnosis allows the obtainment of a reliable serology result ${ }^{42}$. The variation in the concordance between serologic tests may occur due to the incidence of reactivity between closely related trypanosomes, such as Trypanosoma rangeli and Leishmania spp. ${ }^{12,43}$.
The seropositivity of dogs in this study (11.5\%) was lower than that found in areas with the presence of triatomine vectors known to be infected, such Colombia, where $71.6 \%$ of dogs were seropositive through ELISA and IIF techniques, and the State of Ceará, Brazil, where Bezerra et al. found 38\% seropositivity using the same tests ${ }^{44}$. However, similar results to this study were observed in Peru, where the seropositivity in dogs was $12.3 \%$ by ELISA and TESA-blot techniques, and the main vector for the parasite identified in the region was Triatoma infestans ${ }^{45}$. In the State of Piauí, Brazil, the seropositivity obtained by ELISA and IIF was $7.7 \%$, with the species $T$. brasiliensis reported as 
TABLE 2: Prevalence of the variables function, gender, presence of shelter, presence of other animals, and presence and infection by T. cruzi in triatomines with seropositive dogs for Chagas disease in rural areas.

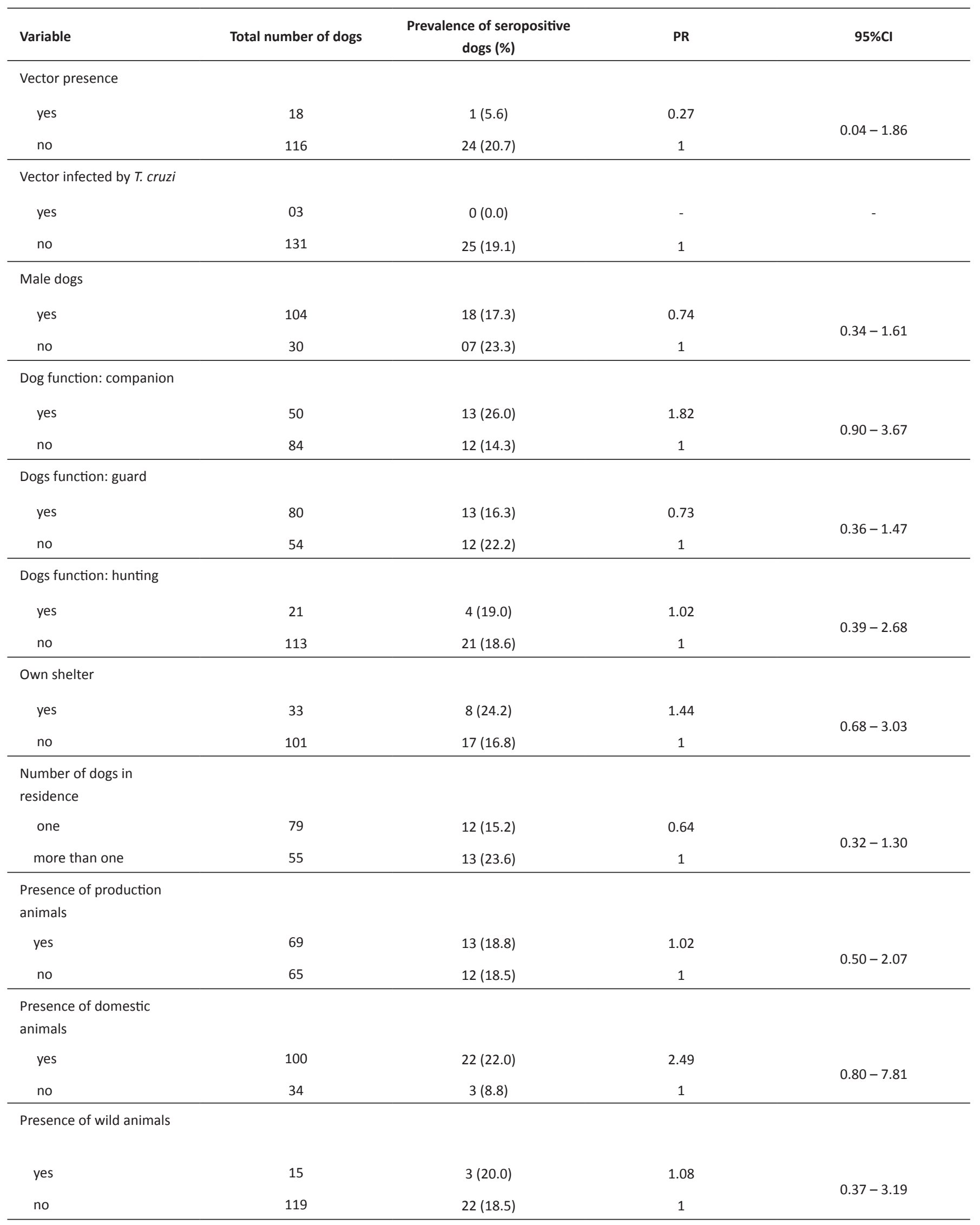

PR: prevalence ratio; $95 \% \mathrm{Cl}$ : 95\% confidence interval. 

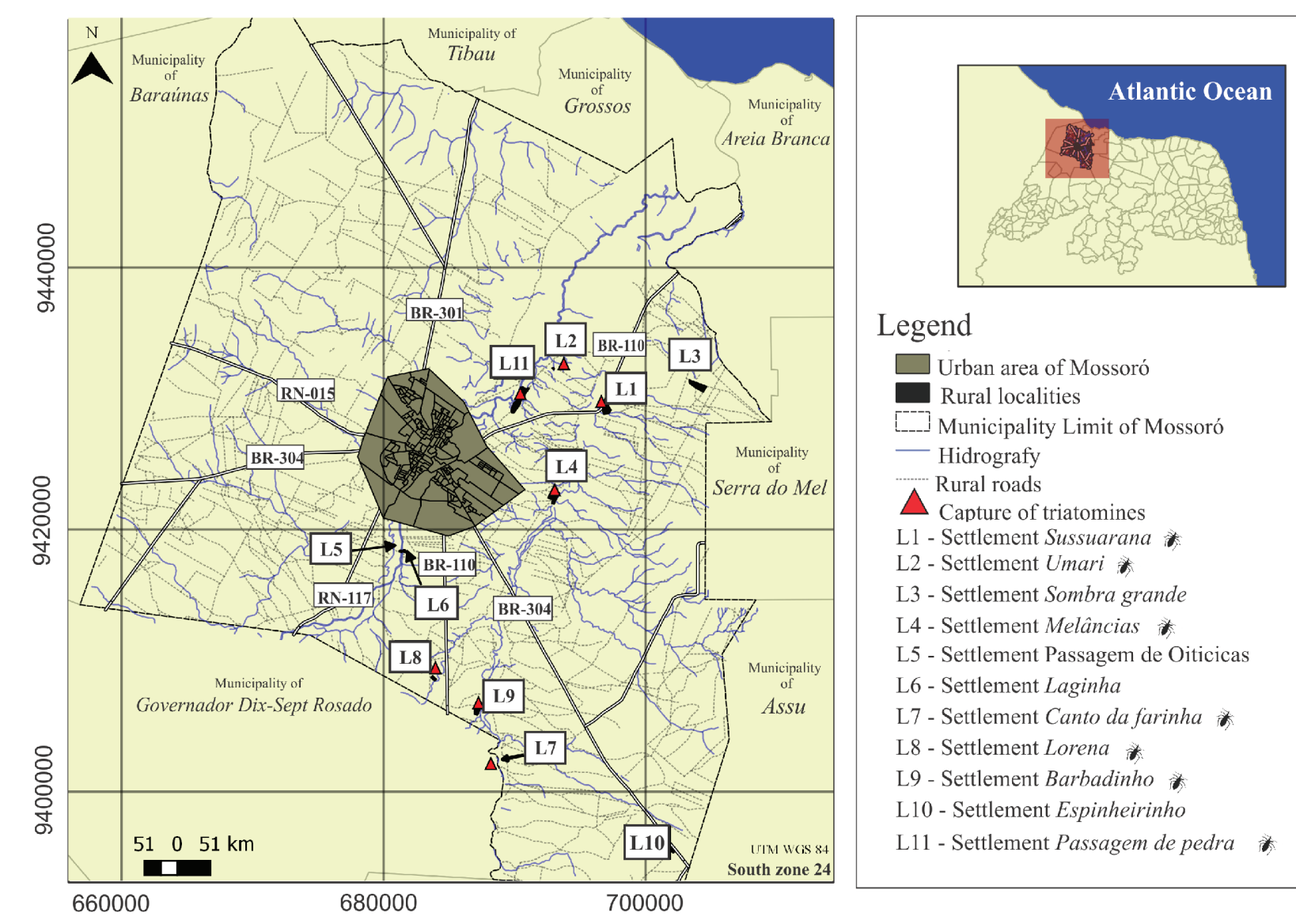

Legend

$\square$ Urban area of Mossoró

Rural localities

Municipality Limit of Mossoró

- Hidrografy

Rural roads

$\triangle$ Capture of triatomines

L1 - Settlement Sussuarana

L2 - Settlement Umari

L3 - Settlement Sombra grande

L4 - Settlement Melâncias *

L5 - Settlement Passagem de Oiticicas

L6 - Settlement Laginha

L7 - Settlement Canto da farinha

L8 - Settlement Lorena

L9 - Settlement Barbadinho

L10 - Settlement Espinheirinho

L11 - Settlement Passagem de pedra

FIGURE 1: Mapping of rural localities of Mossoró, Rio Grande do Norte with triatomine capture history between 2008 and 2012 , highlighting localities with active entomologic capture of triatomines and infection by Trypanosoma cruzi.

the main vector ${ }^{46}$, as in the present study. The difference in seropositivity between the studies may be associated with the abundance of certain vector species in each region, based on ideal climatic, environmental, and geographic conditions for the survival and reproduction of each species ${ }^{47}$. Thus, the triatomine species, the $T$. cruzi prevalence, and the behavior of the dogs are factors that may influence the risk of infection in $\operatorname{dogs}^{48}$.

In regards to seropositivity in dogs, the health status of the dogs, due to poor nutrition and immunosuppression, may be directly reflected in the antibody levels ${ }^{39,40}$. Therefore, the differences between regions need to be considered when evaluating the transmission cycle of T. cruzi in home areas, since socioeconomic indexes and infection risks are directly related ${ }^{49}$.

No relation between the presence of seropositive dogs and that of infected triatomine vectors was observed in this study (Table 2). These factors cannot be discarded, however, since the domiciliation of triatomines and the circulation of T. cruzi between humans and domestic and wild animals are crucial to the establishment of infection. The availability of domestic hosts in households may directly affect the vector's choice of food source, reducing human-vector contact rates and transmission of the parasite ${ }^{50}$.

The mapping of vectors (Figure 1) allows the spatial observation of areas with $T$. cruzi infection and helps the local health services in the control and surveillance of these areas $^{14}$. Geoprocessing techniques have been widely used to understand epidemiological aspects of $\mathrm{CD}$ vectors, including characterization of the areas where the disease is present $t^{51-53}$ and the relation between its distribution and reservoirs ${ }^{29,34}$. This reinforces the importance of the data observed in this study.

The spatial arrangement of triatomines reaffirms the presence of $\mathrm{CD}$ vectors in the environment in some rural areas and confirms the presence of natural infection by $T$. cruzi in these insects, along with diagnosing seropositive dogs. Although no association between seropositive dogs and the presence and infection of triatomine vectors was found, a domestic cycle of the disease is still possible. These results emphasize the importance of epidemiologic monitoring and surveillance of $\mathrm{CD}$, since the health of domestic animals, especially dogs, and their close relationship with humans reflect the health and the level of exposure of local residents to the vector. 


\section{Acknowledgments}

The authors gratefully acknowledge the Department of Health Surveillance and Zoonoses Control Center Mossoró/RN, Allany Medeiros Fernandes, and Edinaidy Moura Rocha. We acknowledge the Federal University of SemiÁrido for the logistical support. We thank the Laboratory of Protozoology and Immunomodulation of the Oswaldo Cruz Foundation for the collaborative work. We also acknowledge the Higher Education Personnel Improvement Coordination for the support of this research.

\section{Conflict of interest}

The authors declare that there is no conflict of interest.

\section{Financial support}

This work was supported by the Higher Education Personnel Improvement Coordination.

\section{REFERENCES}

1. Chagas C. Tripanosomíase americana: forma aguda da moléstia. Mem Inst Oswaldo Cruz. 1916;8(2):37-60.

2. Souza AI, Paulino-Junior D, Sousa MG, Camacho AA. Aspectos clínico-laboratoriais da infecção natural por Trypanosoma cruzi em cães de Mato Grosso do Sul. Cienc Rural. 2008;38(5):1351-56.

3. Dos Reis D, Monteiro WM, Bossolani GDP, Teston APM, Gomes ML, de Araújo SM, et al. Biological behaviour in mice of Trypanosoma cruzi isolates from Amazonas and Parana, Brazil. Exp parasitol. 2012;130(4):321-9.

4. Argolo AM, Felix M, Pacheco R, Costa J. Doença de Chagas e seus principais vetores no Brasil. $1^{\mathrm{a}}$ edição. Rio de Janeiro: Imperial Novo Milênio; 2008. 67p.

5. Bustamante DM, De Urioste-Stone SM, Juárez JG, Pennington PMM. Ecological, social e biological risk factors for continued Trypanosoma cruzi transmission by Triatoma dimidiata in Guatemala. PLoS One. 2014;9(8):e104599.

6. Curtis-Robles R, Lewis BC, Hamer SA. High Trypanosoma cruzi infection prevalence associated with minimal cardiac pathology among wild carnivores in central Texas. Int J Parasitol Parasites Wildl. 2016;5(2):117-23.

7. Tome RO, Gaio FC, Generoso D, Menozzi BD, Langoni H. Active surveillance of canine visceral leishmaniasis and american trypanossomiasis in rural dogs from non-endemic area. Rev Bras Parasitol Vet. 2011;20(1):64-6.

8. Gürtler RE, Cecere MC, Vázquez-Prokopec GM, Ceballos LA, Gurevitz JM, Del Pilar Fernández M, et al. Domestic animal hosts strongly influence human-feeding rates of the Chagas disease vector Triatoma infestans in Argentina. PLoS Negl Trop Dis. 2014;8(5):e2894.

9. Mott KE, Mota EA, Sherlock I, Hoff R, Muniz TM, Oliveira TS, et al. Trypanosoma cruzi infection in dogs and cats and household seroactivity to $T$. cruzi in a rural community in northeast Brazil. Am J Trop Med Hyg. 1978;27(6):1123-7.

10. Garcia MN, O’Day S, Fisher-Hoch S, Gorchakov R, Patino R, Arroyo TP, et al. Uma interação entre saúde de vetores da doença de Chagas, hospedeiros de canídeos e residentes humanos ao longo da fronteira Texas-México. PLoS Negl Trop Dis. 2016;10(11):e0005074.

11. Gürtler RE, Cardinal MV. Reservoir host competence and the role of domestic and commensal hosts in the transmission of Trypanosoma cruzi. Acta Trop. 2015;151(1):32-50.
12. Umezawa ES, Souza AI, Pinedo-Cancino V, Marcondes M, Marcili A, Camargo LMA, et al. TESA-blot for the diagnosis of Chagas disease in dogs from co-endemic regions for Trypanosoma cruzi, Trypanosoma evansi and Leishmania chagasi. Acta Trop. 2009;111(1):15-20.

13. Herrera CP, Licon MH, Nation CS, Jameson SB, Wesson DM. Genotype diversity of Trypanosoma cruzi in small rodents and Triatoma sanguisuga from a rural area in New Orleans, Louisiana. Parasit Vectors. 2015;8:123. doi: 10.1186/s13071-015-0730-8.

14. Rengifo-Correa L, Stephens CR, Morrone JJ, Téllez-Rendón JL, González-Salazar C. Understanding transmissibility patterns of Chagas disease through complex vector-host networks. Parasitology. 2017;144(6):760-72.

15. Lent H, Wygodzinski PW. Revision of the Triatominae (Hemiptera, Reduviidae) and their significance as vectors of Chagas' disease. Bull Am Mus Nat Hist. 1979;163(3):123-520.

16. Sambrook J, Russel DW. Purification of PCR products in preparation for cloning. CSH Protoc. 2006;2006(1):pii:pdb.prot3825. doi: 10.1101/pdb.prot3825.

17. Rendell VR, Gilman RH, Valencia E, Galdos-Cardenas G, Verastegui M, Sanchez L, et al. Trypanosoma cruzi-infected pregnant women without vector exposure have higher parasitemia levels: implications for congenital transmission risk. PLoS One. 2015;10(3):e0119527.

18. Camargo ME. Fluorescent antibody test for serodiagnosis of American trypanosomiasis. Technical modification employing preserved forms of Trypanosoma cruzi in a slide test. Rev Inst Med Trop São Paulo. 1966;8(5):227-34.

19. Zicker F, Smith PG, Luquetti AO, Oliveira OS. Mass screening for Trypanosoma cruzi infections using the immunofluorescence, ELISA and haemagglutination tests on serum samples and on blood eluates from filter-paper. Bull World Health Organ. 1990;68(4):465-71.

20. Enriquez GF, Cardinal MV, Orozco MM, Lanati L, Schijman AG, Gurtler RE. Discrete typing units of Trypanosoma cruzi identified in rural dogs and cats in the humid Argentinean Chaco. Parasitol. 2013;140(3):303-8.

21. Lauricella MA, Castañera MB, Gürtler RE, Segura EL. Immunodiagnosis of Trypanosoma cruzi (Chagas' disease) infection in naturally infected dogs. Mem Inst Oswaldo Cruz. 1998;93(4);5017.

22. Ventura-Garcia L, Roura M, Pell C, Posada E, Gascón J, Aldasoro E, et al. Socio-cultural aspects of Chagas disease: a systematic review of qualitative research. PLoS Negl Trop Dis. 2013;7(9):e-2410.

23. Grijalva MJ, Terán D, Dangles O. Dynamics of sylvatic Chagas disease vectors in coastal Ecuador is driven by changes in land cover. PLoS Neg1 Trop Dis. 2014;8(6):e-2960.

24. Urioste-Stone SM, Pennington PM, Pellecer E, Aguilar TM, Samayoa G, Perdomo HD, et al. Development of a communitybased intervention for the control of Chagas disease based on peridomestic animal management: an eco-bio-social perspective. Trans R Soc Trop Med Hyg. 2015;109(2):159-67.

25. Villela MM, Pimenta DN, Lamounier PA, Dias JCP. Avaliação de conhecimentos e práticas que adultos e crianças têm acerca da doença de Chagas e seus vetores em região endêmica de Minas Gerais, Brasil. Cad Saude Publica. 2009;25(8):1701-10.

26. Gurgel-Gonçalves R, Pereira FDCA, Lima IP, Cavalcante RR. Distribuição geográfica, infestação domiciliar e infecção natural de triatomíneos (Hemiptera: Reduviidae) no Estado do Piauí, Brasil, 2008. Rev Pan-Amaz Saude. 2010;1(4):57-64.

27. Gurgel-Gonçalves R, Galvão C, Costa J, Peterson AT. Geographic distribution of Chagas disease vectors in Brazil based on 
ecological niche modeling. J Trop Med. 2012;2012(1):1-15. doi: $10.1155 / 2012 / 705326$

28. Silva MBA, Barreto AVMS, Silva HAD, Galvão C, Rocha D, Jurberg J, et al. Synanthropic triatomines (Hemiptera, Reduviidae) in the state of Pernambuco, Brazil: Geographical distribution and natural Trypanosoma infection rates between 2006 and 2007. Rev Soc Bras Med Trop. 2012;45(1):60-5.

29. Hernández C, Salazar C, Brochero H, Teherán A, Buitrago LS, Vera $\mathrm{M}$, et al. Untangling the transmission dynamics of primary and secondary vectors of Trypanosoma cruzi in Colombia: parasite infection, feeding sources and discrete typing units. Parasit Vectors. 2016;9(1):2-12.

30. Coutinho CFS, Souza-Santos R, Teixeira NFD, Georg I, Gomes TF, Boia MN, et al. An entomoepidemiological investigation of Chagas disease in the state of Ceará, Northeast Region of Brazil. Cad Saude Publica. 2014;30(4):785-93.

31. Valença-Barbosa C, Lima MM, Sarquis O, Bezerra CM, AbadFranch F. Modeling disease vector occurrence when detection is imperfect II: Drivers of site-occupancy by synanthropic Triatoma brasiliensis in the Brazilian Northeast. PLoS Negl Trop Dis. 2014;8(5):e2861.

32. Waleckx E, Gourbière S, Dumonteil E. Intrusive versus domiciliated triatomines and the challenge of adapting vector control practices against Chagas disease. Mem Inst Oswaldo Cruz. 2015;110(3): 324-38.

33. Waleckx E, Camara-Mejia J, Ramirez-Sierra MJ, Cruz-Chan V, Rosado-Vallado M, Vazquez-Narvaez S, et al. An innovative ecohealth intervention for Chagas disease vector control in Yucatan, Mexico. Trans R Soc Trop Med Hyg. 2015;109(2):143-9.

34. Mendes-Pereira J, Almeida PS, Sousa AV, Moraes de Paula A, Machado RB, Gurgel-Gonçalves R. Climatic factors influencing triatomine occurrence in Central-West Brazil. Mem Inst Oswaldo Cruz. 2013;108(3):335-41.

35. Vinhaes MC, de Oliveira SV, Reis PO, de Lacerda Sousa AC, Silva RA, Obara MT, et al. Assessing the vulnerability of Brazilian municipalities to the vectorial transmission of Trypanosoma cruzi using multi-criteria decision analysis. Acta Trop. 2014;137(1): 105-10.

36. Bezerra RC, Amato Neto V. Trypanosoma cruzi, hemocultura: uma abordagem prática. Rev Bras Clin Med. 2010;8(3):205-7.

37. Castro AM, Luquetti AO, Rassi A, Rassi GG, Chiari E, Galvão LM. Blood culture and polymerase chain reaction for the diagnosis of the chronic phase of human infection with Trypanosoma cruzi. Parasitol Res. 2002;88(10):894-900.

38. Peterson JK, Bartsch SM, Lee BY, Dobson AP. Broad patterns in domestic vector-borne Trypanosoma cruzi transmission dynamics: synanthropic animals and vector control. Parasit Vectors. 2015;8(1):537.

39. Enriquez GF, Bua J, Orozco MM, Wirth S, Schijman G, Gürtler RE, et al. High levels of Trypanosoma cruzi DNA determined by qPCR and infectiousness to Triatoma infestans support dogs and cats are major sources of parasites for domestic transmission. Infect Genet Evol. 2014;25(1):36-43.

40. Balan LU, Yerbes IM, Piña MAN, Balmes J, Pascual A, Hernández $\mathrm{O}$, et al. Higher seroprevalence of Trypanosoma cruzi infection in dogs than in humans in an urban area of Campeche, Mexico. Vector Borne Zoonotic Dis. 2011;11(7):843-4.

41. Gürtler R, Cecere M, Lauricella M, Cardinal M, Kitron U, Cohen J. Domestic dogs and cats as sources of Trypanosoma cruzi infection in rural northwestern Argentina. Parasitology. 2007;134(1):69-82.

42. Sessa PA, Pimentel, RR, Ferreira AL, Falqueto A. Soroprevalência da doença de Chagas em crianças em idade escolar do estado do Espírito Santo, Brasil, em 1999-2000, 2002. Cad Saude Publica. 2002;18(6):1765-9.

43. Matos HJ, Pinto AYN, Miranda AMM, Silva FLC, Ramos FLP. Reação cruzada nos testes sorológicos entre doença de Chagas e leishmaniose visceral em regiões endêmicas para ambas as doenças. Rev Pan-Amaz Saude. 2015;6(1):65-68.

44. Bezerra CM, Cavalcanti LP, Souza RD, Barbosa SE, Xavier SC, Jansen AM, et al. Domestic, peridomestic and wild hosts in the transmission of Trypanosoma cruzi in the Caatinga area colonised by Triatoma brasiliensis. Mem Inst Oswaldo Cruz. 2014;109(7): 887-98.

45. Castillo-Neyra R, Chou Chu LC, Quispe-Machaca V, Ancca-Juarez J,Malaga Chavez FS, Bastos Mazuelos M, et al. The potential of canine sentinels for reemerging Trypanosoma cruzi transmission. Prev Vet Med. 2015;120(3-4):349-56.

46. Perez TD, Figueiredo FB, Velho Jr AA, Silva VL, Madeira MF, Brazil RP, et al. Prevalence of American trypanosomiasis and leishmaniases in domestic dogs in a rural area of the municipality of São João do Piaú, Piauí State, Brazil. Rev Inst Med Trop São Paulo. 2016;58(1):79.

47. Barbabosa-Pliego A, Gil PC, Hernández DO, Aparicio-Burgos JE, de Oca-Jiménez RM, Martínez-Castañeda JS, et al. Prevalence of Trypanosoma cruzi in dogs (Canis familiaris) and triatomines during 2008 in a sanitary region of the State of Mexico, Mexico. Vector Borne Zoonotic Dis. 2011;11(2):151-6.

48. Jiménez-Coello M, Guzmán-Marin ES, Ortega-Pacheco A, AcostaViana KY. Serological survey of American Trypanosomiasis in dogs and their owners from an urban area of Mérida Yucatán, México. Transbound Emerg Dis. 2010;57(1-2):33-6.

49. Fung HL, Calzada J, Saldaña A, Santamaria AM, Pineda V, Gonzalez K, et al. Domestic dog health worsens with socioeconomic deprivation of their home communities. Acta Trop. 2014;135(1):67-74.

50. Gürtler RE, Cardinal MV. Reservoir host competence and the role of domestic and commensal hosts in the transmission of Trypanosoma cruzi. Acta trop. 2015;15(1):32-50.

51. Costa J, Dornak LL, Almeida CE, Peterson AT. Distributional potential of the Triatoma brasiliensis species complex at present and under scenarios of future climate conditions. Parasit Vectors. 2014;7(1):238.

52. Garza M, Arroyo TPF, Casillas EA, Sanchez-Cordero V, Rivaldi CL, Sarkar S. Projected future distributions of vectors of Trypanosoma cruzi in North America under climate change scenarios. PLoS Negl Trop Dis. 2014;8(5):e2818.

53. Medone P, Ceccarelli S, Parham PE, Figuera A, Rabinovich JE. The impact of climate change on the geographical distribution of two vectors of Chagas disease: Implications for the force of infection. Philos Trans R Soc Lond B Biol Sci. 2015;370(1665):pii: 20130560. 